\title{
Teaching High Altitude Military Medical Geography Produces Effective Military Physicians for the Chinese Plateau
}

\author{
Xingshu Chen, Yu Wu, Yu Chen, Chao Tan, Xinyuan Liu, Caizhi Tang, Ze Zeng, Rui Wang, \\ Yongjun Luo*
}

Department of Military Medical Geography, Army Medical Training Base, Army Military Medical University, Chongqing, China

Email address:

ajun-333333@163.com (Yongjun Luo)

*Corresponding author

\section{To cite this article:}

Xingshu Chen, Yu Wu, Yu Chen, Chao Tan, Xinyuan Liu, Caizhi Tang, Ze Zeng, Rui Wang, Yongjun Luo. Teaching High Altitude Military Medical Geography Produces Effective Military Physicians for the Chinese Plateau. Science Journal of Education.

Vol. 7, No. 4, 2019, pp. 91-94. doi: 10.11648/j.sjedu.20190704.13

Received: August 3, 2019; Accepted: September 5, 2019; Published: September 19, 2019

\begin{abstract}
The natural environment at high altitude triggers plateau diseases. This requires excellent military physicians that have graduated from high altitude military medical training to serve people on the plateau. High altitude military medical undergraduates need to complete a variety of military medicine courses. High altitude military medical geography is an important subject in military medicine that focuses on the relationship between the high altitude geographical environment and the health and medical support of military members. Considering military medical geographic information is a key aspect before military actions. This article summarizes the experience of teaching a high altitude military medical geography program, which has produced Chinese military medical undergraduates with excellent theoretical knowledge and practical skills. Our teaching process includes the first and second class levels. The former comprises theoretical and practical courses, including investigations in the field, practice on the plateau, and practice with geographic information systems. During the first class level teaching process, theoretical knowledge was reorganized and combined into four modules. After moving to the second class level, which last for 2-3 years, students continue to develop their military medical geography expertise under the guidance of teachers in summer school. This characteristic teaching mode supports the training of excellent high altitude military physicians for China.
\end{abstract}

Keywords: High Altitude, Military Medical Geography, Medical Undergraduates, Teaching

\section{Introduction}

The Qinghai-Tibet Plateau is the largest and highest plateau in China and accounts for about one-quarter of China's landmass [1-2]. The average altitude is more than 4000 meters, and there are many snowy mountains and glaciers. The Qinghai-Tibet Plateau has low oxygen, low pressure, and high wind speed. It is dry and cold, with strong solar and ultraviolet radiation [3-4]. These factors constitute a major threat to human health. On graduation from our university, military medical undergraduates or military physicians serve the army on the Qinghai-Tibet Plateau. Moreover, military physicians are not just physicians, but must also be competent leaders. This means they need to develop a deep understanding and knowledge of high altitude military medical geography.

High altitude military medical geography is concerned with the effects of the specific natural and social environment of the plateau on the health and hygiene of military members [5-8]. After about 20 years of development, our department has established a characteristic teaching model for high altitude military medical geography. This model has played an important role in training excellent military physicians to serve on the plateau. This article summarizes the characteristics of the high altitude military medical geography training that has produced Chinese military physicians with excellent theoretical knowledge and practical skills.

The teaching process includes first and second class teaching levels. The first class level comprises theory and 
practice, including investigation in the field, practice on the plateau, and geographic information systems (GIS) practice. In the second class level, which lasts for 2-3 years, students develop their military medical geography expertise under the guidance of teachers in summer school, mainly based on seminars held in the earlier level.

\section{Teaching of Theoretical Knowledge in High Altitude Military Medical Geography}

Because of the limited time available and large number of topics to cover, theoretical knowledge relating to military medical geography was reorganized and grouped into four parts. 1) The high altitude environment and human health in China. This part presents a detailed description of the physical geography, landform, meteorological elements, hydrological elements, and vegetation characteristics, as well as the population, ethnic groups, religion, living customs, and the impact of political and economic geography on military health service. 2) The high altitude geographical environment and diseases. This part provides a comprehensive and systematic introduction to the types of high altitude diseases, distribution characteristics of natural focus diseases, parasitic diseases, and common biogeochemical diseases of the plateau. 3) Disaster medical geography. This section introduces the geographical characteristics of disasters and common medical rescue measures. 4) Military medical geographic information technology. This part explains the purpose and importance, content, organized method, investigation, requirements, and common technologies of military medical geographic investigation in military medical geographic research and service.

\subsection{Case-based Teaching Method}

Case-based teaching is used as a teaching strategy [9-10]. We prepare various cases of high altitude military medical geography. Students are guided to preview and participate in discussing these cases. For example, the medical rescue and relief effort following the Yushu earthquake was used as a case for the Qinghai-Tibet Plateau. First, teachers asked students questions pertaining to that real-life scenario (Table 1). Students then discussed the case thoroughly, considering the geographic environment of Yushu Autonomous Prefecture, which is on a plateau with an average altitude of over 4200 meters. A key consideration was that rescuers rapidly entering the plateau were likely to experience acute plateau disease. As military physicians, students need to understand how to effectively manage the prevention and control of plateau disease. Prevention and control of local and natural epidemic diseases should also be considered. As military medical leaders, the students were required to consider all factors pertaining to the natural and social geographic environment on the plateau and work out preparatory measures and rescue plans so the rescue team could reach the earthquake center and safely perform rescue work. The socioeconomic status of Yushu is relatively low. During the earthquake disaster, large-scale traffic paralysis and transport inconvenience resulted in lack of food, water, and medicine. A large number of casualties needed to be urgently treated and evacuated to other cities, meaning logistics had to be carefully planned.

Table 1. Case materials and guidance.

\begin{tabular}{lc}
\hline Case & Questions \\
\hline $\begin{array}{l}\text { On April 14, 2010 at 7:49 am Beijing time, an earthquake of } \\
\text { magnitude 7.1 happened in Yushu Autonomous Prefecture, }\end{array}$ & $\begin{array}{l}\text {. What are characteristics of the natural geographical environment in Yushu } \\
\text { Autonomous Prefecture, Qinghai Province? }\end{array}$ \\
$\begin{array}{l}\text { Qinghai Province, killing at least 150 people in a short time. More } \\
\text { than 3000 people were injured. Local health resources were }\end{array}$ & $\begin{array}{c}\text { 2. What is the social economic status and how does the traffic and transport, distribution } \\
\text { of medical resources in Yushu Autonomous Prefecture? }\end{array}$ \\
$\begin{array}{l}\text { severely damaged, and the medical rescued system was nearly } \\
\text { paralyzed. }\end{array}$ & $\begin{array}{l}\text { 3. How many military medical geographic factors should be considered during medical } \\
\text { rescue and drawing up medical support measures? }\end{array}$ \\
\hline
\end{tabular}

\subsection{Seminar Teaching Method}

A seminar refers to a class at a college or university in which the teacher and a small group of students discuss a topic. Seminar teaching gives students a leading role and is conducive to cultivating students' leadership ability [11]. Teachers are responsible for the initial process, including selection of content, layout of tasks, and organizing the discussion and summarization. As students will have different areas of interest, teachers should permit them to take the lead in the process of searching, reading, and presenting literature. The topics are typically advanced, scientific, and closely related to the teaching content of the four parts of the theory course. Students are required to summarize relevant references. Teachers give suggestions and provide help in searching and summarizing literature, and presenting the findings. Students play the leading role in the discussion, with teachers offering additional supplements and corrections as needed during the class.

\section{Investigation in the Field and Practice on the Plateau}

Medical undergraduates complete practice in the field and on the plateau. Students test the local soil to evaluate its hardness, moisture, acidity and alkalinity, trace elements, water turbidity, residual chlorine, and chemical oxygen demand. Students also learn to test total bacterial and E. coli counts, and investigate the types of medically relevant insects and the way in which transmission of bacteria occurs. After each practice session, each group analyzes and reports the data obtained. These activities help undergraduates to adapt more readily to postgraduate learning. Students gain a better understanding through this hands-on approach than from only 
reading textbooks, especially given their participation in investigations and the related communication. In addition, investigation and practical experience in the field and practice on the plateau can help students better understand the plateau. It also helps to engage them in medical and preventive work when they work on the plateau after graduation.

\section{GIS Practice Class}

The fourth part of our theoretical teaching concerns the techniques of military medical geographic investigation using GIS, which is an important technique for practical teaching. GIS is a kind of spatial information system used to collect, store, manage, analyze, and describe the whole or part of the earth's surface and spatial geographical distribution-related data [12]. We set up the following topics using the ArcGIS software platform (Esri, United States). 1) Military medical geographic data collection and database building. 2) Spatial analysis of epidemic data, which fully uses the powerful spatial analysis function of ArcGIS software. For example, spatial clustering and geographic hot spots of tumor incidence data were analyzed to determine the geospatial clustering regularity. 3) Making medical geography thematic maps. Learning to make simple thematic maps with various professional statistical data is also a basic skill that students need to master in experimental courses. Through computer operation in experimental classes, students can master the basic operation and work flow of GIS software, which helps to deepen their understanding of medical geography subject content, research objectives, and fields of application.

\section{The Second Class Level}

Through the first level learning process, especially seminars and practice classes, students develop a strong interest in what they have learned. Some students want to continue to study this content in greater depth. For these students, we offer the second class level. The second class is a teaching activity in which students can opt to participate based on their interest after they complete the first class level course on high altitude military medical geography. The process is set out in Figure 1.

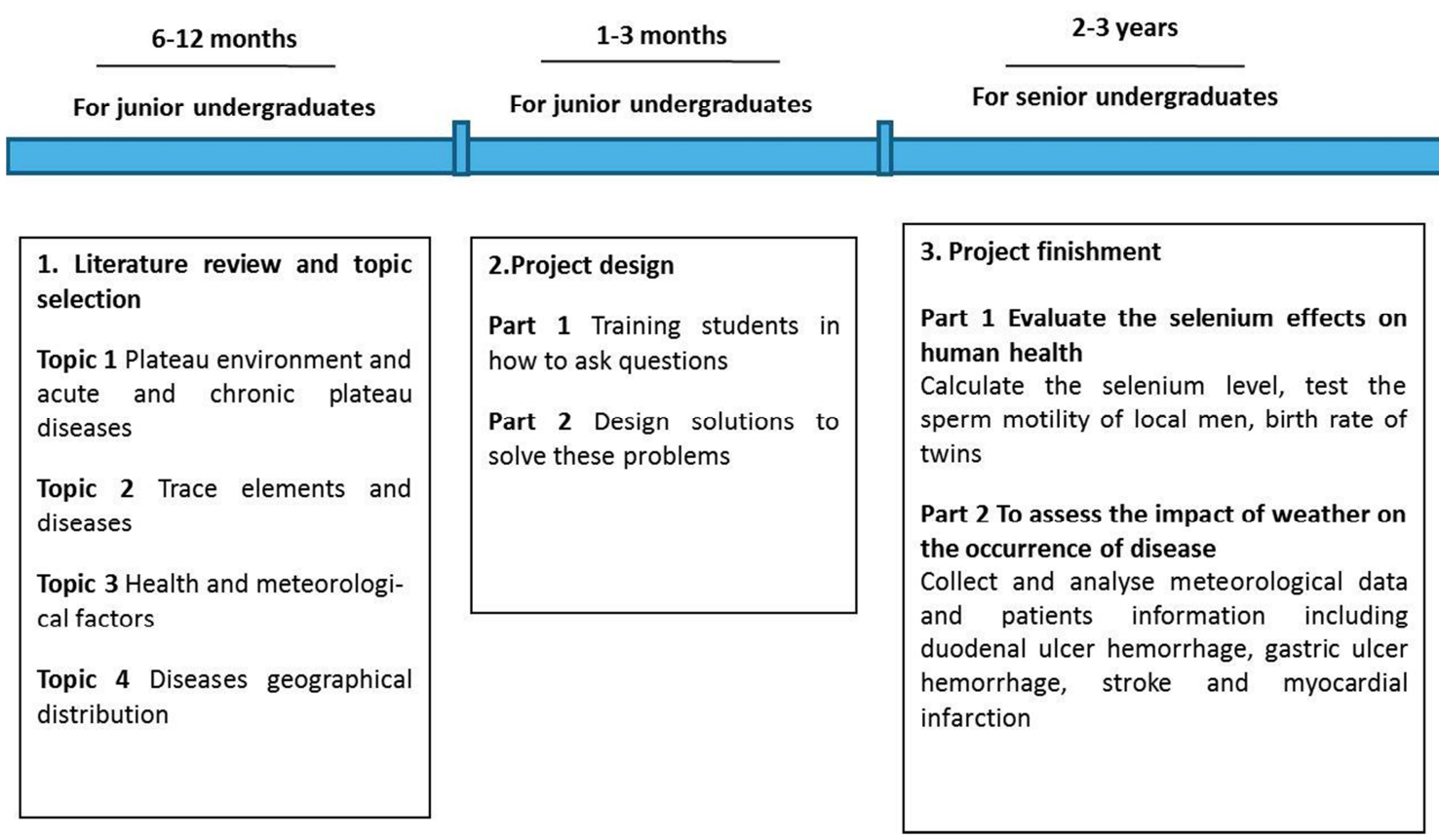

Figure 1. The process for the second class.

\subsection{Literature Review, Topic Selection, and Presentation}

Some students continue with in-depth study based on the content of previous seminars and practice. Other students chose alternative topics based on their own interests, combined with the characteristics of military medical geography and the frontier research direction. For example, they can choose topics such as the plateau environment, acute and chronic plateau diseases, cold areas, and frostbite. They may discuss the relationship between trace elements and diseases in the environment, or the relationship between health and meteorological factors. They could also consider the geographical distribution characteristics and differences in poisonous and harmful plants and animals. Once a topic is selected, students are further instructed about how to extract valuable information from the literature. Students are required to have an understanding of relevant references and form a summary. Finally, findings are presented in the form of a Microsoft PowerPoint presentation. Some students go on to write high-quality reviews, published in domestic or even international journals.

\subsection{Project Design and Application for Innovative Entrepreneurship Projects for Chinese College Students}

After the first stage of literature review and topic selection, 
the second stage involves training students how to ask questions and design solutions to solve problems. Students receive guidance in writing innovative entrepreneurship project proposals and applying for Chinese college student support. According to established requirements, students complete some relatively basic research project applications under the guidance of teachers. In recent years, our students have successively obtained many innovative entrepreneurship projects for Chinese college students, and developed their scientific research and innovation abilities.

\subsection{Group-based Projects Finished in the Summer}

Because little spare time is available during class, students typically finish their projects in summer school. For example, to assess the impact of weather on the occurrence of disease, we instructed students to collect clinical data for patients in the hospital emergency department, including onset time, admission time, and admission signs. Students analyzed the relationship between clinical and meteorological data (e.g., air pressure, temperature, relative humidity, precipitation, somatosensory temperature, and daily temperature difference). The relationship between meteorological factors and duodenal ulcer hemorrhage, gastric ulcer hemorrhage, stroke, or myocardial infarction was also studied. By analyzing these data, students could draw valuable conclusions. Relevant articles have been subsequently published.

\section{Conclusion}

Through a series of teaching models and methods described in this article, we have worked with colleagues from other disciplines to cultivate many excellent plateau medical physicians. A survey showed that these students will be qualified for the role of military medical service leaders or doctors after graduation because they have learned a significant amount of high altitude military medical geography and conducted practice on the plateau during their undergraduate training period [13]. This teaching process encourages effective communication between teachers and students, and gives students opportunities to experience more in-depth perceptions. Students graduate after completing the basic postgraduate training, and many students with strong interest in scientific research choose to continue further postgraduate study. During the period of postgraduate study, students tend to quickly master research methods, and achieve better results than students who did not complete this training.

We have gained good experience and achievements after nearly 20 years of continuous exploration and accumulation of experience. However, improvements are still needed in teaching high altitude military medical geography. For example, more classical cases of high altitude military medical geography are needed. Our undergraduates could also go outside of China to experience the teaching mode and atmosphere of reputable international universities, and participate in international medical geography competitions for undergraduates.

\section{Acknowledgements}

This work was supported by Chongqing Higher Education Teaching Reform Research Project (No. 1963367), Military Medical University Graduate Education Reform Research Project (No. 2018yjgB040). We thank Michelle Pascoe, PhD, from Liwen Bianji, Edanz Editing China (www.liwenbianji.cn/ac), for editing the English text of a draft of this manuscript.

\section{References}

[1] Deng C, Zhang W. Spatiotemporal distribution and the characteristics of the air temperature of a river source region of the Qinghai-Tibet Plateau. Environ Monit Assess, 2018, 190, 368.

[2] Zhang W, Fan Z, Han E, Hou R, Zhang L, Galaverni M, Huang J, Liu H, Silva P, Li P and others. Hypoxia adaptations in the grey wolf (Canis lupus chanco) from Qinghai-Tibet Plateau. PLoS Genet, 2014, 10, e1004466.

[3] Dai X, Shang G, Lu S, Yang J, Xu J. A new subtype of eastern tick-borne encephalitis virus discovered in Qinghai-Tibet Plateau, China. Emerg Microbes Infect, 2018, 7, 74.

[4] Ma Z, Zhao W, Liu M, Liu Q. Responses of soil respiration and its components to experimental warming in an alpine scrub ecosystem on the eastern Qinghai-Tibet Plateau. Sci Total Environ, 2018, 643, 1427-1435.

[5] de Mello JB. [Medical and epidemiological geography. Concepts and definitions]. Hospital (Rio J), 1968, 74, 1707-1721.

[6] de Vries S, Geduld H. Geography should be taught at medical school. S Afr Med J, 2015, 105, 816.

[7] Radic A. [The concept and meaning of military medical geography]. Vojnosanit Pregl, 1966, 23, 531-533.

[8] Valencius CB. Histories of medical geography. Med Hist, 2000, Suppl, 3-28.

[9] Waliany S, Caceres W, Merrell SB, Thadaney S, Johnstone N and Osterberg L. Preclinical curriculum of prospective case-based teaching with faculty- and student-blinded approach. BMC Med Educ, 2019, 19: 31.

[10] Hasamnis AA, Arya A and Patil SS. Case-based Learning: Our Experience in Clinical Pharmacology Teaching. J Pharm Bioallied Sci, 2019, 11: 187-189.

[11] Tricio J, Montt J, Orsini C, Gracia B, Pampin F, Quinteros C, Salas M, Soto R and Fuentes N. Student experiences of two small group learning-teaching formats: Seminar and fishbowl. Eur J Dent Educ, 2019, 23: 151-158.

[12] Eccles KM, Pauli BD and Chan HM. The use of Geographic Information Systems (GIS) for spatial ecological risk assessments: An example from the athabasca oil sands area in Canada. Environ Toxicol Chem, 2019. doi: 10.1002/etc.4577.

[13] Luo Y, Gao Y, Zhou Q, Huang J, Wu C, Luo R. Continuing education in medicine: meeting service needs by improving the effectiveness of medical sergeants' training in 'high altitude sickness treatment and prevention'. J R Army Med Corps, 2014, 160, 260-261. 